\title{
DÜBLIN
}

Technological University Dublin

ARROW@TU Dublin

\section{Meaningful age-friendly design. Case studies on enabling assistive technology.}

\author{
Matteo Zallio \\ Stanford University \\ Damon Berry \\ Technological University Dublin, damon.berry@tudublin.ie \\ Larry J. Leifer \\ Stanford University
}

Follow this and additional works at: https://arrow.tudublin.ie/engscheleart

Part of the Electrical and Computer Engineering Commons

\section{Recommended Citation}

Zallio M., Berry D., Leifer L.J. (2020) Meaningful Age-Friendly Design. Case Studies on Enabling Assistive Technology. In: Ahram T., Falcão C. (eds) Advances in Usability and User Experience. AHFE 2019. Advances in Intelligent Systems and Computing, vol 972. Springer, Cham. DOI: 10.1007/

978-3-030-19135-1_76

This Conference Paper is brought to you for free and open access by the School of Electrical and Electronic Engineering at ARROW@TU Dublin. It has been accepted for inclusion in Conference papers by an authorized administrator of ARROW@TU Dublin. For more information, please contact arrow.admin@tudublin.ie, aisling.coyne@tudublin.ie,gerard.connolly@tudublin.ie.

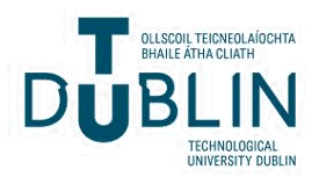




\title{
Meaningful Age-Friendly Design. Case Studies on Enabling Assistive Technology.
}

\author{
Matteo Zallio ${ }^{1, *}$, \\ Damon Berry ${ }^{2}$, and Larry J. Leifer ${ }^{1}$ \\ ${ }^{1}$ Stanford University, Center for Design Research, Mechanical Engineering, 424 Panama \\ Mall, Stanford, CA 94305, USA \\ \{matteo.zallio, leifer\}@stanford.edu \\ ${ }^{2}$ Technological University Dublin, School of Electrical \& Electronic Engineering, Dublin, \\ Ireland \\ damon.berry@TUDublin.ie
}

\begin{abstract}
The world population is steadily ageing and the World Health Organization recently stated that 8.5 percent of people worldwide are aged 65 and over. This cohort is projected to account for 1.6 billion people by 2050 .

Assistive Technology has been developed over previous decades with a particular aim to support people with disabilities.

With the evolution of the market and the introduction of wearable technologies and IoT-based (Internet of Things) appliances, Assistive Technology has been influenced by the discipline of Age-Friendly Design, which has been applied to meaningfully improve the autonomy of a larger segment of the population, including older people.

In order to discuss how Age-Friendly Design can influence the response of the market, and how users can better engage and benefit from Assistive Technology, this work aims to critically review, through a case study research methodology, a series of recently developed devices that have the potential to change user perception around Assistive Technology.

As a conclusion, the reported case studies represent a preliminary validation of how Age-Friendly Design can represent a meaningful solution for enabling a wider group of people with different ages and abilities. Findings show that user experience, satisfaction and Emotional Design are the key drivers for developing marketable solutions in the area of Assistive Technology.
\end{abstract}

Keywords: Assistive Technology $\cdot$ Design Thinking $\cdot$ Usability $\cdot$ Emotional Design · Age-Friendly Design · Inclusive Design · Neurodesign

To cite: Zallio M., Berry D., Leifer L.J. (2019). Meaningful Age-Friendly Design. Case Studies on Enabling Assistive Technology. In: Ahram T., Falcão C. (eds) Advances in Usability and User Experience. AHFE 2019. Advances in Intelligent Systems and Computing, vol 972. Springer, Cham. doi.org/10.1007/978-3-030-19135-1_76. 


\section{Introduction: Towards Age-Friendly Design}

All Over the world, from United States to Europe, Asia to Oceania, countries are experiencing a significant growth of their ageing populations. This trend is associated with increased costs for public healthcare and in OECD (Organization for Economic Co-operation and Development) member countries, people aged 65+, account for 40 to $50 \%$ of healthcare spending and the per capita healthcare costs are three to five times higher than for people under 65 years old [1]. This figure will consistently rise as people aged $80+$ are expected to represent one-twelfth of the whole population by 2039 [2].

However, the recruitment of formal or informal care workers, which seems to be the trend in many developed countries, may not be a sustainable way of facing this intergenerational issue [3].

Older adults, despite their difficulties with using newly-introduced smart devices, can experience a better user experience and an improved feeling of "having control in their hands" by using products designed according to the principles of inclusivity and simplicity of use.

One of the key solutions arising from different national governments policy priorities is the fostering of development of Assistive Technology (AT). AT offers an opportunity for addressing this societal challenge, as well as a means for extending autonomy and well-being of older people and people with different abilities [4]. Over the past decade, innovative technologies such as the Internet of Things and wearable devices have revolutionized the way people behave, communicate and socialize [5]. In particular, AT has been identified as a potential service and aid in delivering care by reducing the expenditure associated with current traditional services $[6,7]$.

AT can now easily provide remote health monitoring, record accurate biofeedback, unobtrusively monitor activities, with sensors and equipment such as fall detectors, door sensors, pressure mats and smoke alarms. It can also enable independence by providing support in performing Activities of Daily Living (ADL), as well as connecting people with doctors and family members [8].

A fundamental aspect, still under investigation by many scientists, focuses on the inclusion of Emotional Design in the development process of AT for the older population. Under the discipline of Emotional Design, as explained by Prof. D. Norman, human beings form emotional connections with objects at three different distinct levels: visceral, behavioral and reflective levels [9]. According to Norman, the visceral level relates to the user's first reactions when they encounter the product, while the behavioral level refers to the usability of the product and finally, the reflective level is concerned with the user's ability to project the product's impact on their lives after the intended use. Emotions play a central role in a person's ability to understand and learn about the world, the objects and services they interact with [9]. The three levels described in Norman's theory, can be easily related to sensations and perceptions. Sensation is the awareness of simple properties of stimuli, such as color. Perception is the awareness of more complex characteristics of the stimuli. For example, noticing the color orange is sensation; recognizing an orange object as being a pumpkin is perception [10].

In relation to the age-related differences, there are changes both at sensation level and at higher levels of perceptual processing [11]. With the wrong technology choices 
and wrong interface design (hardware or software), solutions can be expensive, ineffective, invasive and can result in a product or service that does not satisfy users.

This article aims to briefly analyze and discuss a series of case studies of recent technology solutions developed for the AT market, but with a strong relation to the Age-Friendly Design approach. The discussion focuses particularly on fitness for purpose, usability, efficiency, learnability and design for emotions as key drivers for Age-Friendly designed solutions.

The selection of case studies has been taken from some of the most recent devices presented at the popular Consumer Electronic Show 2019 (CES) aiming to enable customers in different daily activities such as: mobility, sensing, socializing and personal care.

\section{Assistive Technology: an answer to user needs, a market trend or both?}

The innovation activity that accompanies the Internet of Things, when it is combined with the Emotional Design approach, can provide an important contribution for developing new AT for enabling a wider range of the population to live better, safer and more inclusive lives [12]. AT is normally used as an umbrella term to embrace the definition of a wide range of different products and services. Each device has been designed to answer to particular needs of people with disabilities and older people [13]. More specifically, according to the United States Assistive Technology Act of 1998, AT refers to any 'product, device, or equipment, whether acquired commercially, modified or customized, that is used to maintain, increase, or improve the functional capabilities of individuals with disabilities' [14].

The focus on the definition of AT has also been underlined by the World Health Organization (WHO) and its global initiative. The Global cooperation on Assistive Health Technology (GATE) has clarified terms for a more global and inclusive purpose. It defines AT as a concept that includes systems, services and assistive products, whose purpose is to maintain or improve individuals functioning, autonomy and to facilitate participation in social activities [15].

In order to foster a complementary overview of the meaning of AT, the International Standards Organization (ISO) has recently revised the definition of assistive products for persons with disability, integrating the previous definition from 1998 (ISO 9999) with the concepts from the International Classification of Functioning: 'any product (including devices, equipment, instruments and software), especially produced or generally available, used by or for persons with disability for participation, to protect, support, train, measure, or substitute for body functions, structures, and activities, or to prevent impairments, activity limitations, or participation restrictions' [16].

Assistive products are occasionally discussed in the context of technology types overall. In 2017, Smith proposed an inclusive definition of AT, in a separate manner from Therapeutic Technology (TT), Environmental Technology (ET) and Occupational Role Related Technology (ORT) [17].

These terms were delineated based on the purposes of the product and to be inclusive of everyday technological instruments used by general populations as well 
as by people with disabilities. ORT is the technology used by everyone in everyday activities, such as using a telephone, the computer and the television. ET are those used by anyone because they are publicly available in the environment, like lever door handles, elevators, ramps, signs, or public audio messaging. TT are those products that serve to help remediate, teach or improve skills such as strengthening equipment, cognitive training software or educational multimedia. Lastly, AT corresponds to personal products that are used as supports for people to optimize their function, independence and participation in society [17].

Most recent definitions, still under consideration, due to the rapid development of technology and design approaches, state that are no longer the characteristics of the main target user of an assistive product that determines whether the product or service belongs to the category of AT. Instead, modern AT classification depends on whether the purpose of use is to promote well-being and autonomy for a variety of users [18].

Conversely, AT are becoming more and more popular across the broader community. Perhaps this process is due to the increased awareness brought on the market by new devices and services as well as the decreased stigmatization for users with disabilities to use certain universally designed products with AT features.

Nowadays even wearable devices, that provide health information, domestic tools and vehicle adaptations have been accepted by users and inclusive marketing campaigns have promoted the use of AT in a more inclusive way. These new approaches are well represented in different scenarios, in particular regarding the amount of sales and revenue that the AT market can generate in the future decade.

According to a recent major report, the global AT market was valued at approximately USD 18.70 billion in 2017 and is expected to generate revenue of around USD 30.82 billion by end of 2024, growing at a compound annual growth rate of around $7.40 \%$ between 2018 and 2024 [19]. As the market is expected to grow exponentially in the next decade, customer perception, satisfaction and accessibility are all closely related to how products and services can elicit appropriate pleasant emotions.

\section{Methodology: Case study research}

Design research is interdisciplinary and is influenced by engineering, ergonomics, human factors, aesthetics, cognitive science, psychology, economics and medicine [20]. In particular, this activity seeks to explore, observe, analyze, describe, validate, motivate and utilize design knowledge through case studies, user interaction and brainstorming [21]. Case studies are an established research method in social sciences and design thinking and their flexibility, applicability and ease of use have made the case study an empirical research method that can be used to investigate a contemporary phenomenon, focusing on the dynamics of the case, within its real-life context [22]. Different research methods focus on problem definition, hypothesis formation, data collection or data analysis, but the key aspect of case study research is an all-encompassing method that covers all these phases. The case study is a wellvalidated method when the aim of the research is to find answers to "why" and "how" types of questions and behavioral events cannot be controlled [23]. The case studies for this work were initially selected with regard to three specific research questions: 
Why do emotions play a significant role in designing assistive technology? How can meaningful age-friendly design enhance user satisfaction by leveraging design for emotions and usefulness? Where is the assistive technology market going?

Each case study in the analysis follows a detailed, scientifically validated series of steps that refers to three main stages: Define and Design, Collect and Analyze, Summarize and Conclude. Figure 1 shows a representation of the structured methodology used to collect, analyze and evaluate the selected case studies among selected daily activities such as: mobility, sensing, socializing and personal care.

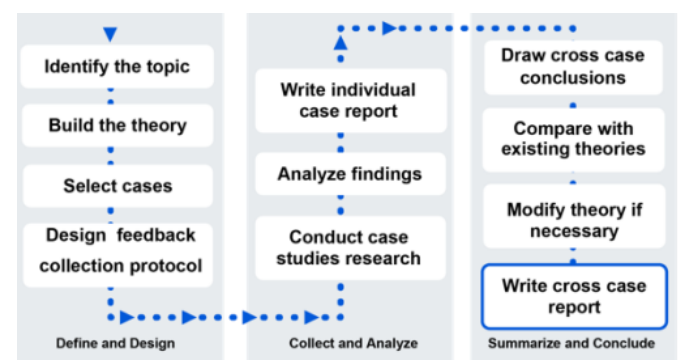

Figure 1. Representation of the case study method, describing detailed steps taken by a researcher while performing a case study.

\section{Case studies for meaningful Age-Friendly Design}

This exploratory work aims to analyze examples of recent AT for the consumer market, by pointing out some of the most relevant features that are driving current Age-Friendly Design innovation. Fitness for purpose, usability, efficiency, learnability and design for emotions are the key topics analyzed through triangulation in areas such as: mobility, sensing, socializing and personal care.

Triangulation (Figure 2), as an approach where different methodologies are involved together, represents one of the major strengths of case study research. Accordingly, triangulated evidence has been collected from multiple sources to corroborate the same fact or finding: observation, information review and discussion with exhibitors, stakeholders and visitors that took part at the CES exhibition.

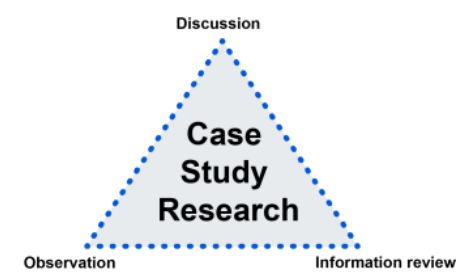

Figure 2. Case study research: triangulation process. Discussion, Observation and Information review. 


\subsection{Case study one: Enabling Mobility}

At the CES 2019, an updated model of an autonomous wheel chair was released. Its name is Whill and the company promise to offer an evolutionary system for personal mobility. Rather than calling their products wheelchairs, Whill refer to them as Personal Electric Vehicles (PEV). This repositioning is intended to bring a fresh, more universal perspective on personal mobility with an innovative design and stateof-the-art technology. The company aims to create a better user experience and confidence to drive anywhere with unprecedented independence and style for all kind of customers.

Whill have released three different models of electric autonomous mobility solutions that span from their Model M, a functionally balanced device with intelligent design for indoor or outdoor application, the Model A, a functionally balanced personal mobility device featuring compact sizes and all-wheel drive and the Model Ci, a compact model with short wheelbase and good for outdoors with a 2 " obstacle clearance.

All three models are based on intelligent driving technology, they each feature a remote control via app and smartphone and the integration of sensors (front and rear mounted cameras) provide ultra-wide-angle obstacle detection. The so called "Accessible Experience" offered by the company, with the help of many advocates and user stories, provides a successful support for the marketing campaign that is driven towards the integration of this mobility solution within airports, hospitals, museums, shopping malls, theme parks and in the future within urban areas.

A fundamental part of the design process for developing the autonomous wheelchair is to involve users in the development, test and marketing phases. Different advocates expressed positive feedback regarding ease of use, through an intuitive joystick or a remote-controlled app via smartphone, an improved efficiency in terms of autonomy and duration of the battery life and the possibility to overcome obstacles and small steps, thanks to a patented wheel-design. This device is intended to improve efficiency in mobility solutions, by creating a pleasant customer experience among primary users but also for the whole population while restoring independence and a confidence to explore. One of the major successes is related to the perception that users, friends and the general public have of this product: the "cool factor" of this solution brings a high level of acceptability and desirability that increases the positive impression of this mobility product, as much as other commonly used technologies have been accepted through the ages.
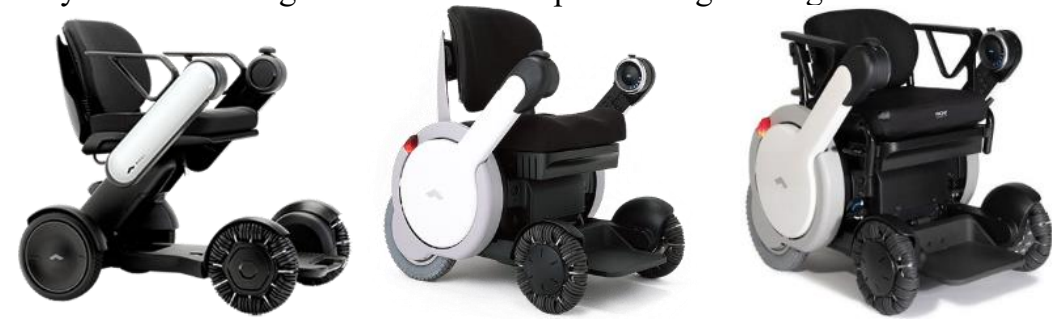

Figure 3. The Whill personal mobility solution fleet. 


\subsection{Case study two: Enabling senses}

According to the World Health Organization (WHO), the estimated number of people visually impaired in the world is 285 million, 39 million blind and 246 million having low vision [24].

A recent development by OrCam, the MyEye 2 (Figure 4) allows blind and visually impaired people to take advantage of some of the most advanced wearable technology to enable them to see and read.

MyEye 2 aims to harness the power of artificial vision by incorporating smart technology into a wearable solution that is applicable to most existing glasses, to improve visual capacity of individuals who have visual difficulties. In detail, the discreet wearable device features different characteristics: read text, such as newspapers, books, menus, signs, product labels and screens, recognize faces with a real time face identification process, identify products by enabling an independent shopping experience, all embedded with an intuitive interface and a compact, ergonomic design.

MyEye 2 has a high level of flexibility and usability as it is a stand-alone device that can be integrated into any pair of glasses through an easy-to-mount system. The user while wearing the pair of glasses with MyEye 2 has to merely point out with a finger what they want to read and the system recognizes the text automatically and reads it for the users. This device, has been tested over the years and a significant number of user cases and advocates have provided feedback such as: "That it's a true enabling technology", "This device is awaking a sense that has been lost during life" or "(It) has never been possible to read (for some visually impaired individual), without MyEye 2". Surprise was recognized as the most relevant reaction during the test with advocates, when they were reading specific content.

The interaction process, made through a hand gesture recognition and a discreet speaker located close to the ear, is simplified compared to other systems. It enables a natural behavior among users and this represents a particular aspect in relation to the design for emotions paradigm. Stakeholders, from selected case studies displayed on the web, reported a set of pleasant emotions when able again to read and interact with documents, products or different people in a group.

This wearable device, has a great potential and the level of accuracy, flexibility and usability, including its miniaturization, this potential will hopefully grow in the foreseeable future, assuring a valid, accepted and user-friendly designed solution for many different customers.

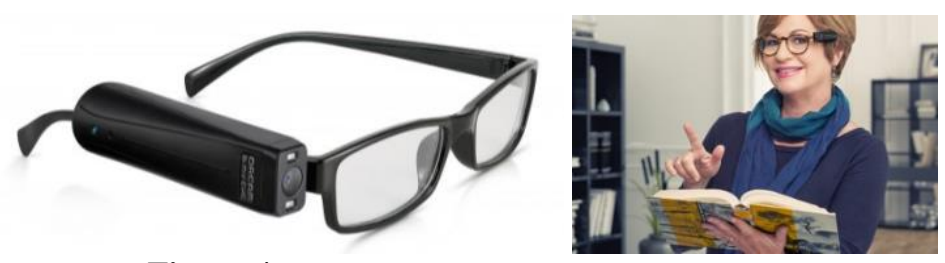

Figure 4. The OrCam MyEye 2 wearable device. 


\subsection{Case study three: Enabling socialization}

LG electronics is putting a lot of work into Artificial Intelligence and robotics for enabling people. In particular, LG demonstrated the full suite of CLOi robots in their natural habitat representations. The family is composed of a GuideBot used to help people to find a store in the mall, a SuitBot used for heavy lifting in a warehouse, the PorterBot to help carry heavy weights, the ServeBot providing room service in hotels, the CartBot to support customers at the shopping market and the CLOi personal assistant, a smart speaker with a cute face as an attempt to make robots more userfriendly.

The important feature that this family of robots is intended to bring to users is the emotional reaction elicited by an assistive device. It can be a pleasant or unpleasant emotion, but spectators to the main show by LG at the CES were offered an unexpected mix of emotions. Amusement, curiosity, surprise, interest, apprehension and admiration were only some of the few emotions perceived among buyers, attendees and exhibitors. The attempt from LG with this set of robots with a pretty humanized facial expression as well as a set of movements that is closely matched to human behavior is to generate impactful and efficient solutions to support the life of people at home, at work and during free time.

The Artificial Intelligence based in the devices helps to support a learning process both for users, in adopting a natural interaction with the robot, as well for the machine, to learn from habits and human behaviors.

LG, with this set of robots has put forward a new way of developing interactive assistive scenarios in different realities, where people, independent of the level of abilities or disabilities they have, can be supported in daily activities. This concept fits very well with the paradigm of Age-Friendly Design where the union of Design Thinking applied to AT and the practice of Emotional Design will strongly support the design and development of user-friendly, adaptable solutions for the future.
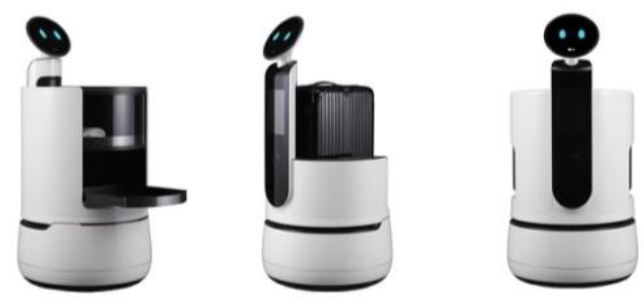

Figure 5. The LG CLOi robot family.

\subsection{Case study four: Enabling well-being}

One impactful problem among senior people and people under treatment or medical cure is to remind them to take pills and drugs every so often. One of the most recently developed products; a companion robot that emotionally interacts with users, family and friends is the Pria companion by Stanley Black+Decker. Pria is an automated medication management and home health assistant controlled by voice 
recognition and smartphone app integration. Pria supports caregivers to monitor an individual's medication and healthcare schedule without interrupting independent lifestyle and serves as a companion and communication device between user, caregivers, family and friends. Pria can proactively facilitate in-home healthcare management services by scheduling different medication doses, provide reminders and alerts, dispensing proper medication at the correct time, tracking visit of doctors and caregivers as well as provide a 24/7 customer service.

This product does not represent a disruptive solution in itself, as many pills dispensers have been manufactured over the years by different competitors. What is innovative about Pria is how easy to learn to use the system is, facilitated by a voice control input and a built-in camera for direct communication with caregivers, as well as an interface designed according to the principles of Emotional Design.

The responsive humanized face displayed on the main screen allows users to feel involved and immersed in a pleasant user experience. By actively interacting with users, Pria offers the ultimate home healthcare tracking and management device, to support independent living and caregivers. Feedback from the large number of visitors attending the launch at the company's booth were constructive, positive and a lot of interest in knowing more about the commercialization date has been demonstrated.

Stanley healthcare intend to debut Pria on the consumer market in 2019.

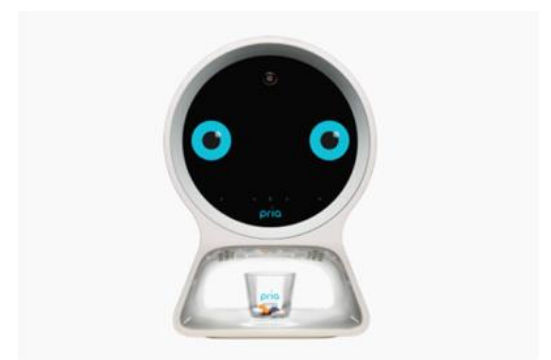

Figure 6. The Stanley Black+Decker Pria pills dispenser.

\section{Discussion: Meaningful Age-Friendly Design}

While a large number of approaches for AT design and decision-making have been implemented in the recent decades, an absence of validity and reliability data related to such approaches emphasizes the importance of understanding potential influences of stigma associated with AT use [25]. Some areas contributing to stigmatization include device aesthetics, gender and age appropriateness, social acceptability, sublimation and professional deference, acceptance of disability, and Universal Design principles [25]. With the latest show on Consumer Electronic, barriers in stigmatization of the use of AT broke down. A broader cross section of people was engaging with devices that would previously be categorized as "pure" AT but are now seen to be more generally applicable and the results of discussions and observations provide a set of contextual information towards the idea of universally designed AT.

AT, particularly when is seen as a set of tools and devices mainly dedicated to persons with disabilities, is now getting a wider consideration among the consumer 
market thanks to a fresher design approach used to develop meaningful user experiences.

The case studies analyzed show how assistive devices with a modest level of engineering innovation (as most of the functionalities have already been launched years ago) have been now designed in a more compelling way, paying massive attention to Emotional Design, learnability, efficiency and needs of primary customers and general audience.

The Design Thinking approach [26], is now a mandatory part of the holistic product development process and the case studies reported in this article showed how the impact of this approach can improve user perception and consequently satisfaction. One further aspect taken in to consideration is the design for emotions approach used to generate pleasant perceptions of the products among customers.

Examples of impacts of the Emotional Design approach in designing those products include "the cool factor" for the autonomous wheelchair and the "surprise" of users for the OrCam device.

Evidences of how an assistive device can be perceived as a universally designed product, rather than a purely AT are feedback such as the recreational value of the fleet of LG robots used in daily life activities and how the integration of simple voice controls and an interactive humanized interface in the Pria device have transformed a traditional drug dispenser in to a companion robot acting similarly to a human caregiver.

All these complex features, coming from different design approaches can be reoriented under the umbrella definition of Age-Friendly Design, where the paradigm of the "Design for eternal youth" incorporates flexibility, efficiency, fitness for purpose, usability and learnability together with some of the most requested feature a product must have nowadays: generate meaningful emotions.

The Age-Friendly Design concept, applicable not only for designing assistive devices, but also in architecture, service design, urbanism, planning, policy design and engineering is a key driver of tomorrow's society. It represents the trait d'union between the design for emotions and good design, explained by Dieter Rams with the famous "Ten principles of good design" [27]: Good design is innovative; Good design makes a product useful; Good design is aesthetic; Good design makes a product understandable; Good design is unobtrusive; Good design is honest; Good design is long lasting; Good design is thorough down to the last detail; Good design is environmentally friendly; Good design is as little design as possible.

When the stigmatization of users using certain devices decreases and the classification of different devices, whether they are assistive devices, enabling devices or simply smart devices, ceases to exist, then it is possible to state that every single product, service or environment is designed accordingly to Age-Friendly principles. What results is a flexible, adaptable solution that answers to the needs of a diversified range of people, no matter what abilities or disabilities they have [28].

\section{Conclusions and future work}

Surprisingly, the greatest potential for improving the lives of the older people lies in technology built for young generations. For example, some impactful development 
that perfectly fits young people needs, such as the smart home, connected cars and the on-demand economy might have a strong impact on older generations.

As a conclusion, the reported case studies represent a preliminary overview of how Age-Friendly Design practice, which embeds the principles of Emotional Design, together with consolidated design practices towards inclusivity, can represent a meaningful solution for enabling a wider group of people with different ages and abilities.

This work represents an exploratory research on how the paradigm of AT is slowly embracing proper approaches of current design practice across different areas (User Experience Design, Interaction Design, Emotional Design and Neurodesign [29]) where the attention to usability, to generate pleasant emotions and to use the brain triggers to help make better informed design decisions based on customer behavior, is becoming fundamental. Examples like the Whill mobility solution - making wheelchairs fun and cool, MyEye 2 - a surprising awakening of sight, LG Robots supportive and intelligent robot friends, and Pria - cuteness for prescriptions support leave space to envisage further development in Age-Friendly Design. An important aspect that came out during this preliminary study is to design for developing emotional experiences in order to better meet customer needs as well as innovate in a fast-growing market. This will help to drive the design process of Assistive Technology towards impactful solutions usable by the majority of customers, by disrupting the stigmatization and general perception of current assistive products.

Acknowledgments. This research has been possible through the Fulbright-Schuman Fellowship, administered by the Commission for Educational Exchange between the United States of America, Belgium and Luxembourg and jointly financed by the U.S. State Department and the Directorate-General for Education and Culture of the European Commission. A joint team from Stanford University (USA) and the Technological University Dublin (Ireland) has been working under the internationally cooperation and cross-cultural principles.

\section{References}

1. Safiliou-Rotschild, C.: Are Older People Responsible for High Healthcare Costs. In CESifo Forum - Institute for Economic Research, Munich, 1/2009, 58-64 (2009)

2. United Kingdom Office for Statistics, https://www.ons.gov.uk/peoplepopulationandcommunity/populationandmigration/populatio nestimates/articles/overviewoftheukpopulation/july2017

3. Zigante, V.: Informal care in Europe. Exploring Formalisation, Availability and Quality. In: Employment and Social Governance Unit A.4 - Thematic Analysis London School of Economics and Political Science. EUROPEAN COMMISSION Directorate-General for Employment, Social Affairs and Inclusion Directorate (2018)

4. United Kingdom Government, https://www.gov.uk/government/publications/harnessingtechnology-to-meet-increasing-case-needs,

5. Morrar, R., Arman, H., \& Mousa, S. 2017. The Fourth Industrial Revolution (Industry 4.0): A Social Innovation Perspective. Technology Innovation Management Review, 7(11), 1220 (2017)

6. Rose, D. H., Hasselbring, T. S., Stahl, S., Zabala, J.: Assistive Technology and Universal Design for Learning: Two Sides of The Same Coin. In: D. Edyburn, K. Higgins, and R. 
Boone (eds.), Handbook of Special Education Technology Research and Practice. White Bay, WI: Knowledge by Design, Inc., 507-511 (2005)

7. Duff, P., Dolphin, C.: Cost-benefit Analysis of Assistive Technology to Support Independence for People with Dementia - part 2. Technology Disability 19, 79-90 (2007)

8. Miskelly, F. G.: Assistive technology in Elderly Care Age and Ageing. British Geriatrics Society 30, 455 - 458 (2001)

9. Norman, D.: The Design of Everyday Things. Basic Books Inc. New York NY USA (2002)

10. Rogers, W. A., Stronge, A. J., Fisk, A. D.: Technology and Aging. 166 Reviews of Human Factors and Ergonomics Volume: 1 issue: 1, 130-171 (2005)

11. Schneider, B. A., Pichora-Fuller, M.: Implications of perceptual deterioration for cognitive aging research. In F. I. M. Craik \& T. A. Salthouse (Eds.), Handbook of aging and cognition, 2nd ed., pp. 155-219. Mahwah, NJ: Erlbaum (2000)

12. Kuru, H., Kuru, A.: Exploring Possibilities of Designing Virtual Personal Health Coach in Relation to Gender Differences. In: DUXU 2014: Design, User Experience and Usability. User Experience Design for Everyday Life Applications and Services pp 63-71, Springer (2014)

13. WHO (World Health Organization). A Glossary of Terms for Community Health Care and $\begin{array}{llll}\text { Services for Older } & \text { Persons, }\end{array}$ http://whqlibdoc.who.int/wkc/2004/WHO_WKC_Tech.Ser._04.2.pdf

14. United States Government Printing Office, https://www.gpo.gov/fdsys/pkg/PLAW108publ364/html/PLAW-108publ364.htm

15. GATE. Global Cooperation on Assistive Technology (GATE), http://www.who.int/phi/implementation/assistive_technology/phi_gate/en/

16. ISO 9999:2016 Assistive Products for Persons with Disability-Classification and Terminology (6th ed.). Brussels, BE: CEN (2016)

17. Smith, R. O.: Technology and occupation: Past, present, and the next 100 years of theory and practice. In: Am J Occup Ther. 2017;71:7106150010 pp1-71 (2017)

18. Federici, S., Scherer, M. J.: Assistive Technology Assessment Handbook. CRC Press 2017

19. Zion Market Research https:/globenewswire.com/newsrelease/2018/09/04/1565309/0/en/Global-Disabled-and-Elderly-Assistive-TechnologyMarket-Worth-USD-30-82-Billion-By-2024-Zion-Market-Research.html

20. Tobi, H., Kampen, J. K.: Research Design: The Methodology for Interdisciplinary Research Framework. In: Quality \& Quantity International Journal of Methodology. Volume 52, Issue 3, 1209-1225 (2018)

21. Blessig, L.: What is this thing called Design Research? In: Proceedings of 2002 International CIRP design seminar, Hong Kong, 16-18 May 2002, pp 1-6 (2002)

22. Yin, R.K.: Case study research: Design and Methods, Sage Publications, Thousand Oaks, CA (2003)

23. Teegavarapu, S., Summers, J., Mocko, G.: Case Study Method for Design Research: A Justification. In: Proceedings of the ASME Design Engineering Technical Conference. 4. 10.1115/DETC2008-49980 (2008)

24. World Health https://www.who.int/blindness/GLOBALDATAFINALforweb.pdf

25. Parette, P., Scherer, M.: Assistive Technology Use and Stigma. In: Education and Training in Developmental Disabilities, vol. 39, no. 3, 2004, pp. 217-226. JSTOR (2004)

26. Lewrick, M., Link, P., Leifer, L. J.: The Design Thinking Playbook: Mindful Digital Transformation of Teams, Products, Services, Businesses and Ecosystems. Hoboken, NJ Wiley (2018)

27. Vistoe, The power of Good Design, https://www.vitsoe.com/us/about/good-design

28. Kelly, P., Zallio, M., Duarte, B., Berry, D.: Design for Enabling Technologies. A Framework to Empower Multi-level User Engagement. In: Di Bucchianico G. Advances in Design for Inclusion. AHFE 2018. Advances in Intelligent Systems and Computing, vol. 
776. Springer, International Conference on Applied Human Factors and Ergonomics, July 2018, Orlando, Florida, USA (2018)

29. Kirkland, L.: Using Neuroscience to Inform Your UX Strategy and Design, in: July 9, 2012. https://www.uxmatters.com/mt/archives/2012/07/using-neuroscience-to-inform-your-uxstrategy-and-design.php 